\section{Constituintes químicos e atividade antiespermatogênica em folhas de Austroplenckia populnea(Celastraceae)}

\author{
Sidney Augusto Vieira Filho ${ }^{1,3 *}$; Lucienir Pains Duarte'; Grácia \\ Divina de Fátima Silva'; Renata Mazaro²; Luiz Cláudio Di \\ Stasi ${ }^{2}$
}

${ }^{1}$ Departamento de Química, ICEx, UFMG, Belo Horizonte, MG

${ }^{2}$ Instituto de Biociências de Botucatu, UNESP, Botucatu, SP

${ }^{3}$ Departamento de Farmácia, UFOP, Ouro Preto, MG, Brazil

gdfsqui@dedalus.lcc.ufmg.br

idistasi@ibb.unesp.br

bibo@dedalus.lcc.ufmg.br

\section{Resumo}

Folhas de Austroplenckia populnea (mangabarana, marmelinho do campo) foram submetidos a estudo fitoquímico. Do extrato hexânico foram isolados e identificados três triterpenos pentacíclicos e um sesquiterpeno agarofurânico inédito. Realizou-se testes de atividade antiespermatogência utilizando parte deste extrato. Os resultados mostraram uma redução significativa do número de espermatozóides no epidídimo.

Austroplenckia populnea Reiss (Celastraceae) é uma árvore tropical amplamente encontrada em Minas Gerais, Brasil, onde é conhecida popularmente por "Mangabarana", "Mangabeira-brava" e "Marmelinho do Campo". Apresenta casca lisa com altura máxima de $10 \mathrm{~m}$ e folhas alternas serreadas oblongas, longo pecioladas, glabras, puntiformes, com $8-10 \mathrm{~cm}$ de comprimento e $4-5 \mathrm{~cm}$ de largura ${ }^{1}$. Suas flores são esverdeadas ou amareladas, dipostas em cimeiras axilares ou subterminais e o fruto é uma sâmara grande e pendente.

O decocto das folhas de Austroplenckia populnea é usado na medicina popular como antidisentérico ${ }^{2}$. Alguns constituintes isolados da planta são citados na literatura como antitumoral (câncer de pele) $)^{3}$ e antibacteriano ${ }^{4}$.

Dando continuidade ao estudo dos efeitos biológicos, realizou-se uma verificação da atividade antiespermatogênica de A. populnea, utilizando o extrato hexânico obtido das suas folhas $^{5}$. Paralelamente, este extrato foi submetido a processos fitoquímicos que permitiram o isolamento de 3 triterpenos pentacíclicos: friedelina (I) ${ }^{6}, \beta$-friedelinol (II) ${ }^{7}$ e 28 -hidroxifriedelina (III) ${ }^{8}$ e um sesquiterpeno agarofurânico inédito: $4 \beta$ hidroxi-1,2,6,15-tetraacetil-9-benzoil-agarofurano (IV) (figura 1).

As substâncias foram caracterizadas por espectrometria no UV, RMN de ${ }^{1} \mathrm{H}$ e ${ }^{13} \mathrm{C}$ e por CG-EM.

Os números de espermatozóides no epdídimo de ratos tratados com o extrato hexânico de Austroplenckia populnea estão registrados na Tabela 1 . Verificou-se que ocorreu uma redução significativa no número de espermatozóides presentes no epidídimo dos ratos submetidos ao teste. Neste experimento não foram observadas alterações na morfologia dos espermatozóides.
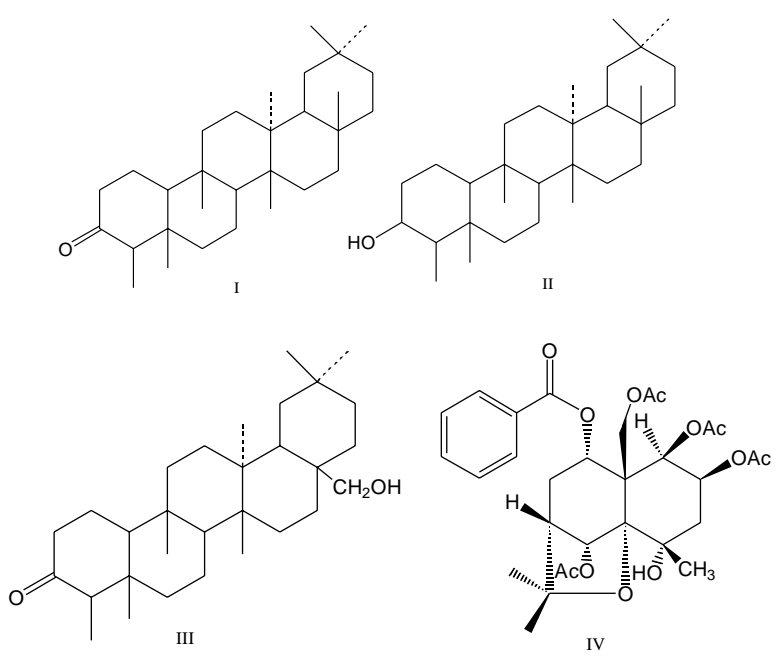

Figura 1. Terpenos isolados de A. populnea.

Tabela 1. Número de espermatozóides no epidídimo de ratos tratados com EH de Austroplenckia populnea

\begin{tabular}{l|l|l}
\hline Grupos & \multicolumn{2}{|c}{$\mathrm{n}^{\circ}$ espermatozóides* } \\
\hline & Absoluto/órgão & Relativo/g órgão \\
\hline Controle & $341,95 \pm 15,86$ & $1450,00 \pm 42,86$ \\
EH & $269,73 \pm 11,51$ & $1243,33 \pm 29,26$ \\
\hline
\end{tabular}

* $\mathrm{n}=8$, média \pm EPM, $(\mathrm{p}<0,01)$. Teste Turkey-Kramer

A presença significativa de triterpenos pentacíclicos no extrato hexânico da planta sugere que tais substâncias possam ser responsáveis pela atividade biológica apresentada pelo extrato.

\section{Material e Métodos}

Material vegetal: As folhas de Austroplenckia populnea foram coletadas na região de Nova Lima - Minas Gerais no período de julho e agosto de 1996. Após identificação botânica, foi preparada uma exsicata que foi depositada, sob o número 10473 , no Herbário do Museu de História Natural da Universidade Federal de Minas Gerais, em Belo Horizonte - Minas Gerais.

Extração e fracionamento das folhas: As folhas foram secadas à temperatura ambiente e depois pulverizadas em moinho de facas. A seguir, 178,6 g foram submetidas à extração contínua com hexano em aparelho Soxhlet. Após a remoção do solvente obteve-se $26,8 \mathrm{~g}$ de extrato.

O extrato hexânico das folhas de Austroplenckia populnea foi cromatografado em coluna de gel de sílica (1 kg), sendo coletadas 275 frações de $500 \mathrm{ml}$ cada, utilizando para eluição, hexano, clorofórmio, acetato de etila e metanol puros ou em mistura de polaridade crescente.

As frações 62-65 (408,3 mg), Fr 68-75 (1612,5 mg) e Fr 
122-143 $(203,6)$ foram lavadas com acetona levando à obtenção de friedelina (I), $\beta$-friedelinol (II) e 28-hidroxi-friedelina (III), respectivamente.

A fração 240-245 (622,3 mg) foi recromatografada em coluna de sílica gel (230-400 Mesh, para cromatografia rápida) utilizando como eluente hexano-acetato de etila (9:1) originando 25 frações. A fração 14 foi purificada por cromatografia em camada delgada preparativa $\left(\mathrm{CHCl}_{3} / \mathrm{EtOAc} 65: 35\right)$. O constituinte que apresentou $R f$ 0,65 foi separado e lavado com hexano levando à obtenção do sesquiterpeno (IV).

Teste de atividade antiesparmatogênica: Uma parte do extrato hexânico $(\mathrm{EH})$, dissolvida em óleo de girassol, foi inoculada (1,0 g/kgpc/dia, p.o. via cânula) em ratos Wistar machos e adultos, durante 14 dias. Posteriormente os testículos foram seccionados em três partes, sendo a mediana fixada em solução de Karnovsky e as demais em ALFAC. Cortes histológicos de $3 \mathrm{~mm}$ foram corados em hematoxilina/eosina e analisados por ensaio cego (aleatorizados por outro experimentador).

\section{Referências}

${ }^{1}$ Fátima Silva GD, "Constituintes Químicos de Austroplenckia populnea: Estrutura molecular e de cristal e ensaios farmacológicos", Tese de doutorado. Departamento de Química, ICEx, UFMG. 1990; 274 p

${ }^{2}$ Correa MP. Dicionário das Plantas Úteis do Brasil. Vol. V Ministério da Agricultura, RJ. 1969; 152

${ }^{3}$ Monache FD. Populnonic acid, a new triterpenic acid with friedelane carbon skeleton. Gaz. Chim. Ital. 1972; 102: 636-646

${ }^{4}$ Vieira Filho SA, Duarte LP, Paes HCS, Silva GDF, Sousa JR \& Lanna MCS. Antibacterial Activity of Pentacyclic Triterpenes from Austroplenckia populnea. Acta Horticulturae. 1999; 501: 199-203

${ }^{5}$ Mazaro R, Di Stasi LC, Vieira Filho SA, Kempinas WG, Decrease in sperm number after treatment of rats with Austroplenckia populnea. Contraception. 2000; 62: 45-50

${ }^{6}$ Patra A, Chaudhuri SK, Assignment of carbon - 13 nuclear magnetic resonance spectra of some friedelanes. Magnetic Resonance in Chemistry. 1987; 25, 95-100

${ }^{7}$ Salazar GCM, Silva GDF, Duarte LP, Vieira Filho AS, Lula, IS., Two epimeric friedelane triterpenes isolated from Maytenus truncata Reiss: ${ }^{1} \mathrm{H}$ and ${ }^{13} \mathrm{C}$ chemical shift assignments. Magnetic Resonance in Chemistry. 2000; 38 (11): 977-980

${ }^{8}$ Salazar GCM, "Análise da Constituição Química da Casca da Madeira e Folhas de Maytenus Floribunda". Belo Horizonte, Departamento de Química. ICEx - UFMG. Dissertação de Mestrado. 1993; 93 p

${ }^{9}$ Vieira Filho AS, Duarte LP, Santos MH, Silva GDF, Lula, IS., Afonso RJCF. Complete assignment of the ${ }^{1} \mathrm{H}$ and ${ }^{13} \mathrm{C}$ NMR spectra of a new polyester sesquiterpene from Austroplenckia populnea, Magnetic Resonance in Chemistry. 2000; 38 (11): 1023-1026

\section{Substâncias fenólicas com atividade antioxidante de Pseudopiptadenia contorta (Leguminosae-Mimosoideae)}

\author{
Davyson de Lima Moreira'; Renata L. Engelhardt'; Alexandre \\ da Silva Reis²; Edgar Marteleto Sanches'; Suzana Guimarães \\ Leitão²; Gilda Guimarães Leitão ${ }^{1 *}$
}

${ }^{1}$ Núcleo de Pesquisas de Produtos Naturais, Universidade Federal do Rio de Janeiro, 21941-590, Rio de Janeiro, RJ 2 Departamento de Produtos Naturais e Alimentos, Faculdade de Farmácia, Universidade Federal do Rio de Janeiro, Rio de Janeiro, RJ, Brasil

ggleitao@nppn.ufrj.br

\section{Resumo}

O extrato bruto em acetona/ água das folhas de Pseudopiptadenia contorta foi purificado rendendo frações e substâncias puras. A atividade antioxidante foi avaliada para o extrato e frações, empregando-se o teste químico do DPPH. As frações contendo taninos condensados e substâncias fenólicas de baixo peso molecular mostraram ser as responsáveis pela atividade antioxidante do extrato bruto das folhas de $P$. contorta.

Pseudopiptadenia contorta pertence à família Leguminosae, que possui distribuição geográfica ampla e é representada por 650 gêneros e cerca de 18000 espécies, distribuídas em três subfamílias: Mimosoideae, Papilionoideae e Caesalpinioideae ${ }^{1}$. P. contorta é encontrada em fragmentos de Mata Atlântica no Estado do Rio de Janeiro e faz parte da dieta alimentar do primata folívolo Alouatta fusca ${ }^{2}$. Os radicais livres são espécies reativas associadas como causa ou consequência de inúmeras doenças crônicas, entre elas artrite reumatóide e a aterosclerose. A busca por substâncias antioxidantes naturais vem aumentando nos últimos anos, especialmente após a introdução do extrato padronizado de Ginkgo biloba na terapêutica como antioxidante ${ }^{3}$. A atividade antioxidante pode ser avaliada in vitro com êxito pelo teste do DPPH (2,2-difenil-1picril-hidrazila), um radical livre estável à temperatura ambiente, com coloração violeta característica em solução etanólica ${ }^{4,5}$. A cromatografia em coluna com gel de Sephadex LH-20 do extrato em acetona/ água das folhas de $P$. contorta levou ao isolamento de 6 frações. As frações 1 e 4 foram purificadas por recristalização. $\mathrm{O}$ conjunto de dados espectrométricos $\left(\mathrm{RMN}{ }^{1} \mathrm{He} \mathrm{e}^{13} \mathrm{C}, \mathrm{UV}, \mathrm{APT}\right.$, COSY H-H) obtidos para a substância da fração 1 permitiu identificá-la como o flavonol myricetrina. A substância purificada da fração 4 foi identificada como 2',4-diidroxi-4'metoxichalcona ${ }^{6,7}$. Análise da fração 5 por HPLC-DAD, utilizando-se sistema de solvente próprio para taninos condensados (sistema I $)^{8}$, mostrou a presença de sinais em 19,01 min e entre 25 e $35 \mathrm{~min}$. O espectro de UV desses sinais mostrou 